\title{
CLUBE DE MÃES: ESPAÇO PARA INTERVENÇÃO EM SAÚDE DA MULHER*
}

\author{
Patricia Alves de Senna**

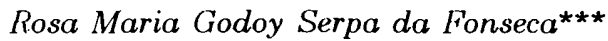

SENNA, P.A. de; FONSECA, R.M.G.S. da Clube de mães: espaço para intervenção em saúde da mulher. Rev.Esc.Enf.USP, v.29, n.1,p.34-46, abr. 1995.

$O$ artigo relata uma pesquisa realizada junto a mulheres integrantes de Clubes de Mães do Distrito Sanitário de Perus, no Município de São Paulo. Teve como objetivos conhecer o seu perfil organizacional, a articulação que mantêm com as instituições de saúde municipais da região e com outros movimentos de mulheres. Ao lado disto pretendeu-se conhecer as concepções de saúde-doença das suas integrantes para verificar as possibilidades para intervenção em saúde coletiva. Os resultados indicam que estas instituições têm um caráter fundamentalmente assistencialista e conservador, revelado também nas concepções de saúde-doença das suas integrantes. Observam-se no entanto, espaços para intervenção no sentido de ampliar a consciência das mulheres acerca da sua identidade social e da saúde da mulher.

UNITERMOS: Mulher. Movimento popular. Saúde da Mulher

\section{INTRODUÇÃO}

Inicialmente, há que se aclarar que para o conhecimento atual dos Clubes de Mães (CM), objeto de estudo deste trabalho, se faz necessária uma breve recuperação histórica da sua existência, bem como das condições em que isto ocorreu, justamente por se acreditar que este é o determinante da sua constituição atual e das características das ações que desenvolvem.

* Pesquisa financiada parcialmente com recursos do programa USP/CNPq

** Aluna do 8o semestre do Curso de Graduação em Enfermagem e Obstetrícia da

Escola de Enfermagem da Universidade de São Paulo. Bolsista de Iniciação Científica do Programa USP/CNPq.

*** Professor Doutor do Departamento de Enfermagem em Saúde Coletiva da Escola de Enfermagem da USP.Orientadora de Bolsa de Iniciação Científica do Programa USP/CNPq. 


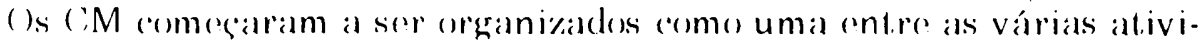

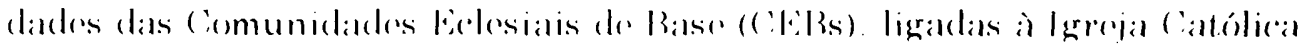
Apostólica Romana, pela preocupação das mesmas com as mulheres, que constituíam a maior parte dos seus participantes.

As Comunidades Eclesiais de Base surgiram nos anos 60, como conseqüência das Diretrizes do Concílio Vaticano II (1966-1968), posteriormente trabalhadas para a América Latina, na Conferência Episcopal de Medellin (1982). Na época, "a Igreja Católica iniciou uma profunda transformação e renovação interna que deu origem a formas novas de ser cristão, levando a repensar as relações com a comunidade e a refletir sobre a caminhada do povo de Deus, até chegar à Teologia da Libertação e à opção preferencial pelos pobres. As CEBs foram então organizadas principalmente nos bairros periféricos, nas favelas, em pequenos sítios da área rural à beira das cidades que fornecem mão-de-obra ao campo."(VIEZZER, 1989)

Na década de 70, os CM já se faziam presentes em várias lutas sociais. Por exemplo, foi em alguns deles, localizados em regiões da Zona Sul de São Paulo, que teve origem o Movimento do Custo de Vida que, posteriormente, se alastrou pelo país e que constituiu um dos movimentos sociais mais abrangentes até 1978. (VIEZZER, 1989)

Apesar dos CM advirem das CEBs, não apresentam o mesmo tipo de evolução, considerando que não se pode pensar nos mesmos como uma realidade homogênea. Assim como alguns deles continuam, até hoje, executando primordialmente suas atividades iniciais relacionadas à realização de trabalhos manuais, estudos bíblicos ou orações, existem outros que se encontram buscando objetivos mais relacionados à vida como um todo, engajados em uma verdadeira busca pela eqüidade social, participando com o restante da coletividade em questões mais amplas, relacionadas à melhoria da qualidade de vida da população, não deixando de lado a importância da articulação política em seu meio.

Esta mesma diversidade ou heterogeneidade na caminhada dos diversos CM, reflete-se nos aspectos relacionados às questões da mulher. Enquanto em alguns destes Clubes, as atividades se direcionam no sentido de reforçar os papéis socialmente impostos à mulher, em outros, a reflexão se faz presente no sentido de construir uma identidade feminina mais liberta destes grilhões.

Descobrir-se mulher e lutar pelos seus direitos de cidadania não é tarefa fácil de assumir, porque o cenário social é sustentado pela ideologia androcêntrica e patriarcal difundida nos âmbitos educacionais, religiosos, científicos e culturais da sociedade, cujo objetivo é manter a mulher subordinada socialmente ao homem.

Assim, se a trajetória de muitos CM está intrinsicamente ligada à Igreja Católica que é a instituição que os mantêm tanto financeira como ideologicamente é de se esperar que a ideologia que eles refletem também seja da 
mesma natureza e que propicia muito mais a alienação das mulheres que a sua emancipação.

Da mesma maneira, a saúde da mulher pode ser encarada de diferentes formas nestes espaços, seja vinculada a uma visão mais ampla de integridade biológico-social, seja dicotomizada ou parcializada.

No entanto, por ser um espaço que mutualmente propicia às mulheres a troca de experiências, muitas oportunidades podem surgir relacionadas às possibilidades de ampliação da sua consciência sobre a própria vida, e ncla sobre a sua saúde.

Por acreditar nesta possibilidade, a finalidade deste trabalho foi descobrir as possibilidades de intervenção, junto às mulheres integrantes destes $\mathrm{CM}$, para ampliar a sua visão de saúde-doença e, indiretamente, a visão da sua condição social da mulher.

Para alcançar esta finalidade, os objetivos traçados foram: conhecer o perfil organizacional dos CM no que se refere aos objetivos e prioridades que direcionam suas ações, bem como o conteúdo das mesmas e a forma de organização do movimento; conhecer as concepções de saúde-doença presentes entre as suas integrantes, verificar a articulação que os CM mantêm com as instituições de saúde municipais da região e com outros movimentos de mulheres. Pretendeu-se também analisar estes dados de acordo com as possibilidades apresentadas para a ampliação ou redução da consciência da mulher em relação à sua identidade social.

\section{METODOLOGIA}

\subsection{A População do Estudo}

A população de estudo foi constituida por mulheres integrantes de sete dos oito CM existentes no Distrito Sanitário de Perus, da $\Lambda$ dministração Regional de Pirituba - Perus (ARS-8) da Secretaria Municipal de Saúde. Esta região foi escolhida em virtude de ser o espaço onde se desenvolve um Projeto de Integração Docente $\Lambda$ ssistencial entre a Escola de Enfermagem da USP e a Prefeitura do Município de São Paulo, através da Secretaria Municipal de Saúde.

Foram entrevistadas especialmente dirigentes destas entidades, uma vez que o esperado 6 que estas seriam as mulheres capazes de fornecer os dados da pesquisa. 
Os dados foram coletados por meio de entrevistas diretivas, com roteiro (anexo I). As entrevistas foram gravadas, posteriormente transcritas e analisadas, com o objetivo de se buscar os dados referentes às variáveis que compunham o estudo.

As perguntas foram precedidas de uma explicação a respeito da pesquisa enquanto suas finalidades e objetivos.

O roteiro foi pré-testado com uma dirigente de um Clube de Mães localizado em uma outra região da cidade (Zona Leste) e modificado de acordo com a necessidade.

\subsection{As variáveis estudadas}

Para alcançar os objetivos propostos, as variáveis estudadas foram as seguintes:

\subsubsection{Caracterização institucional}

- entidade mantenedora

- caracterização da sede

- manutenção financeira

- objetivos do movimento

- prioridades

- historico

- motivação inicial

- forma de organização

- avanços e dificuldades do movimento

- atividades desenvolvidas

- articulação com outros movimentos de mulheres

- articulação com recursos de saúde

2.3.2 Caracterização das participantes

- idade

- sexo

- papel na instituição

- estado civil

2.3.3 Entendimento sobre a saúde da mulher 


\subsection{As etapas do trabalho}

O trabalho foi realizado percorrendo as seguintes etapas:

- identificação dos Clubes de Mães existentes na região delimitada

- contato com as dirigentes com o objetivo de marcar e realizar as entrevistas

- realização das entrevistas (coleta dos dados)

- transcrição das entrevistas

- tabulação e análise dos dados

- elaboração do relatório final da pesquisa

\section{RESULTADOS}

Foram entrevistadas 7 mulheres, representantes de 7 Clubes de Mães do Distrito de Perus. Apesar de muitas tentativas não foi possível ser contactada a pessoa, do oitavo Clube, a ser entrevistada.

Destas entrevistadas, 6 eram coordenadoras e apenas 1 era participante, sem cargo diretivo.

Quanto à caracterização, a idade das participantes variou entre $15 \mathrm{e}$ 70 anos, com uma concentração maior na faixa entre 40 e 50 anos. Quanto ao estado civil, em apenas um deles a totalidade das participantes era casada, apesar dos demais terem relatado que a maioria das participantes tinham esta condição marital.

Quanto à caracterização institucional, todos os Clubes eram vinculados à Igreja Católica Apostólica Romana, 6 possuíam sede própria e 1 ocupava um espaço cedido por uma escola infantil.

Quanto aos objetivos, para quase todos os Clubes, eram de caráter assistencialista, referindo-se principalmente à promoção de ações ligadas à realização de trabalhos manuais ou à ajuda humanitária às pessoas, no sentido de alívio da pobreza. Apenas um preocupava-se em realizar trabalhos destinados à ampliação da consciência da mulher a respeito do seu papel social, referindo-se como objetivos "formar a consciência da mudança do papel da mulher, envolver a mulher na política, na religião e em todos os setores, e conhecer os direitos da mulher".

A listagem dos objetivos dos Clubes de Mães estudados e mostrada a seguir, apesar de nas falas das mulheres, às vezes, os mesmos se confundirem com as ações executadas. 


\section{OBJETIVOS DOS CLUBES DE MÃES}

- costurar roupas, ensinar trabalhos manuais

- conversar, orientar, ajudar a comunidade, ajudar as mães pobrezinhas

-aprender a se defender do marido

- trazer pessoas para a comunidade

- ligar as mulheres à Igreja

-trazer as mulheres para o Clube de Mães

-formar a consciência da mudança do papel da mulher

-envolver a mulher na política, na religião e em todos os setores -conhecer os direitos da mulher

É interessante notar que uma mulher relatou que no Clube de Mães podia "aprender a se defender do marido", sem que no entanto tenha referido outras questões articuladas a esta.

Estes objetivos direcionavam as prioridades no sentido de realizarem empreendimentos da mesma natureza, ou seja, assistencialistas e humanitários, como por exemplo: a realização de bazares (2), a compra de máquinas para a montagem de uma oficina (1), a realização de cursos de pintura e costura (1).

A entidade que tinha objetivos que mostravam a sua aderência a uma política partidária de esquerda, indicou que sua prioridade de ação referiase à reivindicação por escolas, creches e saúde, relatando o desejo, inclusive, de articular-se aos Conselhos Gestores das Unidades de Saúde da Região, na luta pela melhoria da assistência à saúde da população. Uma das entrevistadas não respondeu a esta pergunta, por não compreendê-la.

O histórico destas instituicões foi buscado através da verificação do tempo de existência e da motivação inicial para o empreendimento. O tempo de existência variou de 2 meses a 16 anos, sendo que 3 deles tinham 2 anos ou menos de existência e 3,10 anos ou mais. É interessante notar que o Clube que tinha objetivos mais voltados para a cmancipação da mulher era o mais antigo. Para um deles não foi possível saber o tempo de existência.

A motivação inicial para a formação do movimento, em 3 casos, foi articulada à pessoa fundadora do Clube, como mostram as falas abaixo:

"...no início, o Frei convocava as coordenadoras da comunidade que no caso sou eu, a Maria de Lourdes e pedia prá gente convocar as mulheres prá gente conversar com as mulheres, prá saber o que elas queriam..."

"Iniciou pela Jandira. Ela chamou a gente lá prá costurar roupa, fazer crochê e ensinar as outras mães que não sabem. A Jandira que teve a motivação prá começar. A maioria das mulheres do Clube de Mães são da comunidade." 
"O início foi assim como eu já te falei. A gente fez uma rifa, fez um bingo e a gente comprou todas as coisas que a gente precisava para trabalhar e a gente continuou. As coisas que a gente faz, a gente vende $e$ vai continuando. A idéia partiu da primeira coordenadora."

Duas mulheres desconheciam como o Clube havia se iniciado e outras 2 revelaram um início compatível com a formação de uma organização de mulheres com objetivos político-partidários; para a outra, a motivação inicial foi um curso para a formação de Clubes de Mães promovido pela Igreja Catolica, ministrado por uma Assistente Social e que visava desencadear um movimento com uma nova concepção de Clubes de Mães, não mais assistencialista como era o antigo, mas como um veículo gerador de tomada de consciência para as questões femininas.

Quanto ds formas de organização, 5 Clubes eram constituídos por uma coordenadora e demais participantes, em outro, havia duas coordenadoras e as participantes e no sétimo, coordenadora, secretária e tesoureira, além das participantes.

Todos os Clubes mantinham encontros uma vez por semana, no período da tarde, onde as mulheres desenvolviam trabalhos manuais de crochê, tricô, tapeçaria e costura, mesmo aqueles que referiram atividades com conotação mais política. Aparentemente, os trabalhos manuais constituíam motivo para reunir as mulheres, independentemente dos demais objetivos. As reuniões na parte da tarde eram justificadas pelo fato dos afazeres domésticos das mulheres se concentrarem na parte da manhã.

Quanto às dificuldades enfrentadas, a mais relatada foi a financeira, apontada pela maioria das entrevistadas. Depois, foram apontadas outras: a falta de interesse das mães em participar, o que resulta na evasão; a falta de meios para inovação e a falta de meios para a divulgação do trabalho desenvolvido.

Por conquistas, foram referidas: creche e escola (2); ampliação do conhecimento, amizade e aumento do número de integrantes (1); realização de bazares (1); a consecução de transporte e ambulatório de especialidades médicas para a região (1). Apenas uma mulher referiu como conquista a ampliação da consciência da mulher em relação ao trabalho feminino. Três das entrevistas não referiram conquistas.

Quanto à vinculação a outros Clubes de Mães, apenas 2 referiram esta prática. As demais disseram que ela não existe. Nenhuma delas referiu vínculo com outros movimentos de mulheres.

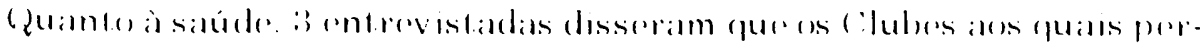

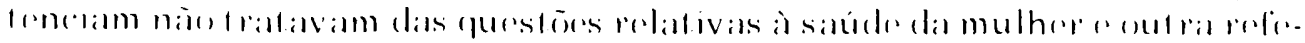

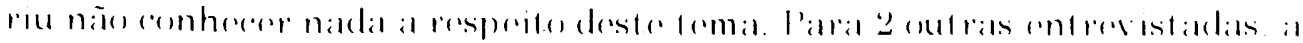




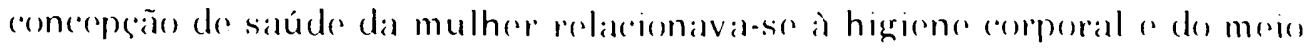

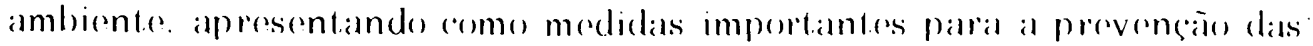

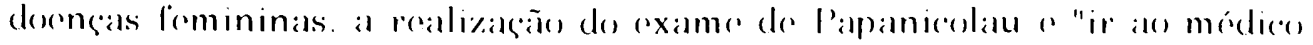

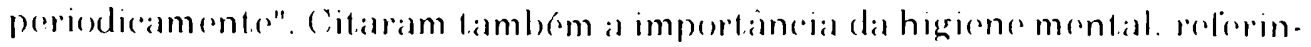

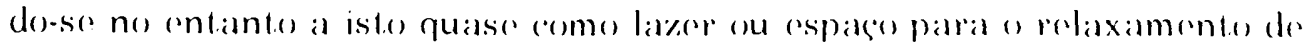

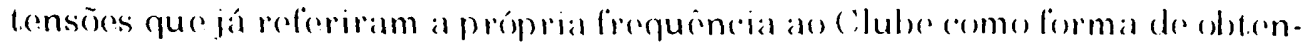

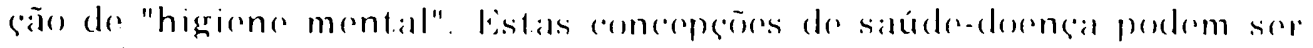
('x(rmplificadas nas laalas al)alixu:

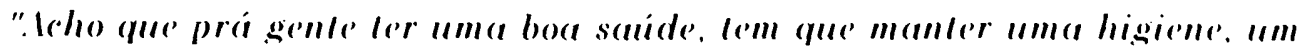

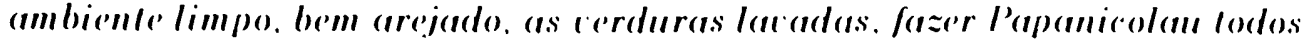
os anos. procurar um l'osto de Sinide"

"...o que a gente mais faz lá (no Clube de Mães) é higiene mental, porque você está numa roda de mulheres, você s? desliga de casa, dos problemas. Acho que isto contribui muito para a higiene mental..."

\section{ANÁLISE E COMENTÁRIOS}

A análise dos resultados evidencia que o trabalho da maioria dos Clubes de Mães tem um caráter fundamentalmente assistencialista e humanitário, devendo-se isto, em parte, ao fato de estarem vinculados à Igreja Católica. Há que se lembrar que esta instituição religiosa, apesar de conservadora, tem demonstrado tendência progressista, representado pela parcela do clero que advoga os princípios da Teologia da Libertação. Ainda assim, hegemonicamente difunde uma ideologia de tendência androcêntrica, o que leva a que mesmo os seus setores mais progressistas pouco possam contribuir para a ampliação da consciência da mulher, no que se refere à sua situação da subalternidade social e os meios para superá-la.

Neste sentido a religião, para os Clubes de Mães, como para toda a sociedade, está mais voltada para a manutenção da realidade, do que para a sua transformação. Para transformá-la, seria necessário "analisar o cotidiano da mulher sob uma perspectiva crítica, afim de buscar a compreensão da relação dialética existente entre o público e o privado, trabalhando essa relação no sentido de entendermos a discriminação da mulher, como expressão das contradições inerentes a uma sociedade de classes e patriarcal". (REDE MULHER, 1988)

"As barreiras à superação da alien ação da mulher não se localizam em sua natureza ou em sua constituição física, como pretende o saber burguês, 
mas resultam da ação das classes dominantes juntamente com o Estado e a Igreja."(RAGO, 1987)

Por serem os Clubes de Mães caracterizados como movimentos de base popular, pouco se pode esperar, de imediato, como resultados favoráveis a uma adequada ampliação da consciência das suas participantes, constituídos majoritariamente por mulheres casadas e mães, enclausuradas na "redoma do lar" com oportunidades restritas de ampliação do seu saber em relação à dimensão social da identidade feminina. Este lar, acaba reproduzindo o sistema social na medida em que referenda a posição secundária da mulher.

Isto pode ser evidenciado mesmo no transcurso histórico dos movimentos sociais que pretendiam a superação de algumas contradições, como na citação abaixo:

"Ao reproduzir a exigência burguesa de que a mulher operária correspondesse ao novo ideal feminino da mãe, "vigilante do lar", o movimento operário obstaculizou sua participação nas entidades de classe, nos sindicatos e no proprio espaço de produção, demandando seu retorno ao campo que o poder masculino lhe circunscreveu: o espaço da atividade doméstica e o exercício da função sagrada da maternidade". (RAGO, 1987)

Desta forma, o que resta à mulher é aproveitar a vivência de participação nos espaços como os Clubes de Mães a fim de abstrair, consciente ou inconscientemente, elementos que sirvam para o preenchimento de sua trajetória de vida.

No entanto, naquele espaço, as suas atividades que, geralmente se resumem em trabalhos manuais, não podem ser vistas como um mero prolongamento dos afazeres domésticos, pois contribuem para um processo que se estabelece a partir do momento em que as mulheres resolvem se reunir. Tal processo pode se encaminhar, em maior ou menor grau, para a busca da identidade feminina, dependendo de como cada Clube faz articular os seus objetivos e prioridades, direcioando suas ações a uma consciência mais transformadora.

Chega-se à conclusão de que a vivência de participação em grupo pode estimular a discussão de algumas questões resultantes do enquadramento da mulher pelo sistema dominador machista. Estas questões se expressam em dois âmbitos que se evidenciam, respectivamente, nos discursos das entrevistadas referentes à necessidade de "se defender do marido" e ao "medo de falar em público", problemas estes ditos superados após a participação nos Clubes de Mães.

O primeiro problema tem suas raízes expressas nos dizeres de $\mathrm{RAC}_{\mathrm{G}}(\mathrm{C}$ (1987): "Estabelece-se então uma relação pedagógica, paternalista, de subordinação da mulher frente ao homem, exatamente como no interior do espaço doméstico. () pai, o marido, o líder devem ser obedecidos e respeitados pelas mulheres, incapazes de assumirem a direção de suas vidas individuais ou 
enquanto grupo social oprimido. (...) Não raro a figura da mulher aparece nesta linguagem associada à da criança, na medida em que ela é infantilizada através da imagem de desamparo, de incapacidade de pensar e de agir, espirito servil por natureza. A imagem da mãe-sacrifício e da criança-inocência completam-se numa construção simbólica." (RAGO, 1987)

A superação disto poderia estar na reflexão das mulheres no sentido de reconhecer que o problema não é individual e insuperável. A troca de experiências poderia também fortalecê-las para enfrentar a superação da subordinação.

Quanto ao segundo problema, também interagir no espaço público pode levar a mulher à superação do mesmo. Relatando um trabalho participativo com mulheres, CARLOTO (1989) cita: "O que é muito importante neste processo é que as pessoas foram perdendo o medo de falar, de pensar, pois am. pliaram sua visão de mundo, conheceram pessoas diferentes, se relacionaram com técnicos, enfrentaram autoridades. Algumas se destacaram como lideranças, tentando puxar o movimento pra frente fazer o grupo refletir mais profundamente os desafios colocados no movimento."(CARLOTO, 1989)

Reflexões da mesma natureza podem ser feitas em relação à percepção das entrevistadas sobre o processo saúde-doença da mulher. Ao situá-lo, primordialmente, no âmbito do biológico, revelam desconhecer a dimensão determinante do social, advindo daí a mesma concepção ingênua em relação a como cuidar da sua saúde.

Ao que tudo indica, este espaço de ação dos CM pouco tem propiciado para a reflexão mais profunda e abrangente sobre a saúde da mulher, parecendo apenas um espaço um pouco mais ampliado do que o lar, em relação a isto, até porque não há a prática de interrelação com outros movimentos de mulheres, nem mesmo da área específica da saúde. No entanto, pode ser um espaço onde postas estas questões, elas consigam ser superadas pela reflexão conjunta a respeito.

\section{POSSIBILIDADES DE ATUAÇÃO PROFISSIONAL}

Diante do observado neste trabalho, acreditamos que este espaço pode ser utilizado em saúde coletiva para atuação em relação às questões da saúde da mulher, especialmente em trabalhos educativos onde o conhecimento vinculado possa instrumentalizar as mulheres a iniciarem em uma trajetoria de compreensão e uma possível transformação da realidade do seu processo saúde-doença.

$\mathrm{Na}$ área da educação em saúde têm sido mostradas amplas oportunidades para isto especialmente no que tange aos aspectos preventivos.(CHIESA, 1994) 


\section{CONSIDERAÇÕES FINAIS}

Este estudo mostrou que os Clubes de Mães pesquisados possuem uma atuação bastante conservadora tanto no que se refere à condição social da mulher como ao seu processo saúde-doença. Apesar disto, as falas das entrevistadas revelam pontos de vulnerabilidade que no espaço coletivo da reflexão poderiam ser trabalhados no sentido de mostrar as contradições existentes, objetivando a ampliação da consciência das mulheres envolvidas. Assim, constituem espaços privilegiados para a atuação em saúde coletiva, dado que denota-se inclusive, uma predisposição favorável das mesmas para isto.

SENNA, P.A. de; FONSECA, R.M.G.S. da Mother's club: health-disease aspects in a women's organization. Rev.Esc.Enf.USP. v.29, n.1, p.34-46, Apr. 1995.

The article relats an investigation realized next to integrant of Mother's Club of the Sanitary District of Perus, in the Municipal of São Paulo. It has how aims to know the its organizacional shape and the relation between locals Municipals health institutions and with other women movements. With this to intended to know the concepts about health disease from their members to verify the possibilities of intervention in coletive health. The results reveal in the conceptions of health-disease of their integrants. Observe, however, spaces to intervention in the feeling to mplify the breast-plate of the women about of the their social identity and of the woman's health.

UNITERMS: Woman. Popular association. Woman's health.

\section{REFERÊNCIAS BIBLIOGRÁFICAS}

CHIESA, A.M. O) uso de estratégias participativas para o conhecimento das representaçoes sociais de mulheres da Regiao de Pirituba/Perus com resultado Classe III de Papanicolau. Sao Paulo, 1994. 160p. I)issertação (Mestrado) Faculdade de Saúde Pública, Universidade de Sao Paulo.

('ARLCOT(), (:.M. et al. Construindo um movimento de saúde. São Paulo, Serviço de Orientaça Familiar (S()F), 1989.

RA(X), M. Do cabaré ao lar: a utopia da cidade disciplinar. 2.ed. Rio de daneiro, Paz e Terra, 1987.

REDE Mulher, Mulheres participando - onde?, Sao Paulo, 1988.

VIEZZER, M. () problema não está na mulher. São Paulo, Cortez, 1989. 


\section{ANEXO I \\ ROTEIRO DE ENTREVISTA}

Formulárion"

1. Nome do Clube de Mães:

2. Endereço:

3.Entrevistado (cargo/responsabilidade dentro do movimento):

4.Entidade Mantenedora:

pública: ( )municipal ( )estadual ( )federal

privada: ( )filantrópica

religiosa: ( ), Qual?

mista: ( ), especifique

não há: ( )

5. Caracterização física:

sede: ( )própria

( )cedida

( )alugada

( )outro(descreva):

6. Como vocês se mantêm financeiramente?

7.Qual o objetivo do Movimento Popular de Mulheres?

8. Quais as prioridades desse Movimento?

9. Você pode relatar um breve histórico do Movimento?

9.1 Tempo de existência:

9.2 Início do Movimento (motivação):

9.3 Formas de organização (estrutura hierárquica):

9.4 Avanços e principais dificuldades do Movimento:

9.5 Caracterização da população participante: sexo: maioria ( )F ( )M

idade:

estado civil: 
10. Existem encontros? Qual o horário? Quem participa desses encontros? De que forma é feita a sua divulgação? $\mathrm{CM}$ ?

11. Quais as principais atividades que vem sendo desenvolvidas pelo

12. O que este CM entende por Saúde da Mulher? O que vocês buscam em termos de saúde?

13. Quais as conquistas que têm sido conseguidas? Como?

14. Existe algum vínculo deste CM com os demais Movimentos de $\mathrm{Mu}$ lheres? Como se dá tal vínculo?

15. O CM mantêm algum contato com postos de saúde desta região?

16. Existe algum representante do CM em outras instâncias de participação popular no sistema de saúde?

17. Existe algum trabalho direcionado para a conscientização dos direitos da mulher? Descreva.

18. Você gostaria de dizer mais alguma coisa sobre a sua experiência neste trabalho junto ao Movimento? 